\title{
Risk factors determining the need for second-look endoscopy for peptic ulcer bleeding after endoscopic hemostasis and proton pump inhibitor infusion
}

Authors

Institutions
Hsiu-Chi Cheng ${ }^{1,2}$, Chung-Tai Wu ${ }^{1,2}$, Wei-Ying Chen ${ }^{1,2}$, Er-Hsiang Yang ${ }^{1,2}$, Po-Jun Chen ${ }^{1,2}$, Bor-Shyang Sheu ${ }^{1,2}$

Institute of Clinical Medicine, National Cheng Kung University Hospital, College of Medicine, National Cheng Kung Univeristy, Tainan, Taiwan

2 Department of Internal Medicine, National Cheng Kung University Hospital, College of Medicine, National Cheng Kung University, Tainan, Taiwan submitted 11. May 2015 accepted after revision 14. December 2015

\section{Bibliography}

Dol http://dx.doi.org/ 10.1055/s-0041-111499 Published online: 8.2.2016 Endoscopy International Open 2016; 04: E255-E262

(c) Georg Thieme Verlag KG Stuttgart · New York E-ISSN 2196-9736

\section{Corresponding author}

\section{Prof. Bor-Shyang Sheu, MD}

Department of Internal

Medicine

National Cheng Kung University Hospital

138 Sheng Li Road, Tainan

Taiwan

Phone: +886-6-2353535 ext. 5368

Fax: +886-6-2370941

sheubs@mail.ncku.edu.tw
Background and study aims: The need for routine second-look endoscopy in cases of peptic ulcer bleeding remains uncertain. We investigated risk factors related to the need for second-look endoscopy after endoscopic hemostasis and proton pump inhibitor (PPI) infusion.

Patients and methods: We prospectively enrolled 316 patients with peptic ulcer bleeding after endoscopic hemostasis. Second-look endoscopy was scheduled after 72-hour PPI infusion (Day-3 subgroup) or one day early (Day-2 subgroup). If early rebleeding developed within 3 days, emergent second-look endoscopy was conducted. Risk factors for early rebleeding (use of E2 ${ }^{\text {nd }}$ score to predict the need for early second-look endoscopy) and persistent major stigmata in the Day-3 subgroup (use of $\mathrm{R} 2^{\text {nd }}$ score to predict the need for routine second-look endoscopy) were analyzed using univariable and multivariable regression.

\section{Introduction \\ $\nabla$}

Peptic ulcer bleeding is a common, yet lethal disease [1]. The appearance of stigmata of recent hemorrhage (SRH) in cases of peptic ulcer indicates a higher rate of peptic ulcer rebleeding [2]. Based on endoscopic management to treat SRH, peptic ulcer rebleeding can be reduced $[3,4]$. To further improve control of rebleeding, the concept of a second-look endoscopy has been proposed [57]. Between the two endoscopic sessions, acid suppression is generally recommended to elevate the intragastric $\mathrm{pH}$ value and thus prevent peptic ulcer rebleeding $[8,9]$. Given the limited scale of the studies and inadequacy of acid suppression because only a histamine- 2 receptor antagonist was applied in these trials [5-7], the exact impact of second-look endoscopy on peptic ulcer rebleeding control remains uncertain [9-11]. With the availability of more potent gastric acid sup-
Results: Excluding 10 of 316 patients with early rebleeding, the rate of persistent major stigmata was lower in the Day-3 subgroup than in the Day-2 subgroup ( $4.8 \%$ vs. $15.4 \%, P=0.002$ ). Endoscopic epinephrine-injection monotherapy and hypoalbuminemia $<3.0 \mathrm{~g} / \mathrm{dL}$ were two independent risk factors for early rebleeding $(P \leq 0.05)$. The Forrest Ia-Ib type and hypoalbuminemia $<3.5 \mathrm{~g} / \mathrm{dL}$ were two independent risk factors for persistent major stigmata on the day-3 second-look endoscopy ( $P$ $<0.05)$. The E2 ${ }^{\text {nd }}$ score was highly accurate for prediction of early rebleeding (AUROC 0.86; $95 \% \mathrm{CI}$, $0.73 \sim 0.99$ ), and the $R 2^{\text {nd }}$ score could predict persistent major stigmata at second-look endoscopy (AUROC 0.84; 95\% CI, 0.69 0.99).

Conclusions: For patients with peptic ulcer bleeding, E2 ${ }^{\text {nd }}$ and $\mathrm{R} 2^{\text {nd }}$ scores can indicate the need for early and routine second-look endoscopy, respectively

(Trial registration identifier: NCT02197039).

pression by proton pump inhibitor (PPI) infusion after endoscopic therapy, a recent consensus suggests that second-look endoscopy should be reserved for certain high-risk patients [12].

After endoscopic treatment for SRH of peptic ulcer, a 72-hour intravenous (IV) PPI infusion followed by oral PPI already has been adopted as the standard approach to prevent peptic ulcer rebleeding [9]. Nevertheless, it has limited effectiveness in certain high-risk patients, such as those with comorbidities $[13,14]$. It is possible that due to poor SRH fading after 72-hour PPI infusion in certain patients, second-look endoscopy may be helpful to retreat SRH. Accordingly, there is a pressing need to elucidate which patient risk factors result in a need for second-look endoscopy in a period when PPI infusion is readily available [15].

The aim of the present study, therefore, was to investigate risk profiles that help identify early re- 


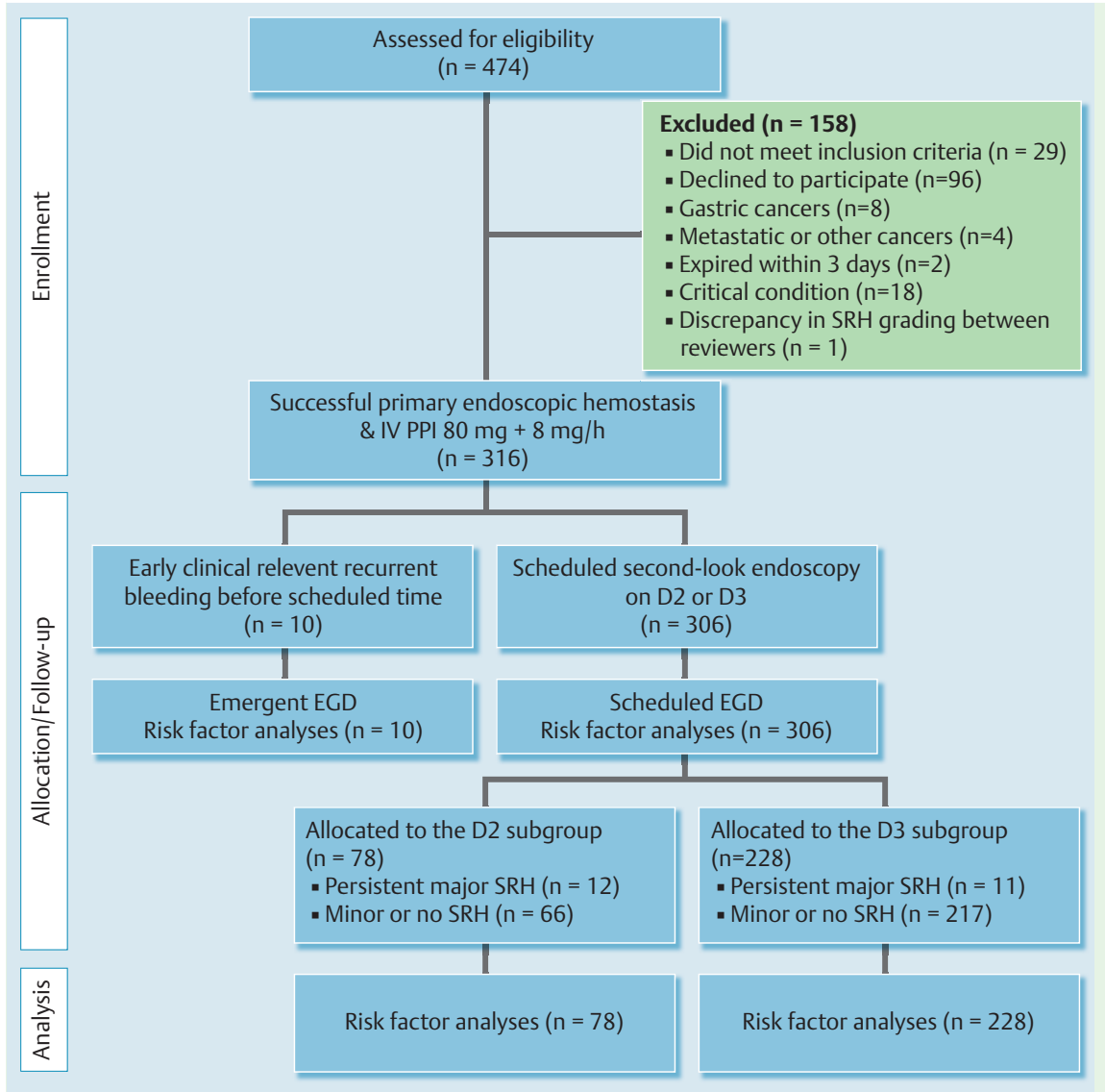

Fig. 1 The schematic flow chart for the study design.

bleeding or poor fading of major SRH in a large cohort of patients with peptic ulcer bleeding after PPI infusion. The study illustrated the independent risk factors related to peptic ulcer rebleeding in order to obtain two scores. These data can help readily identify patients who require either early second-look endoscopy or routine second-look endoscopy to improve control of peptic ulcer rebleeding even after PPI infusion.

\section{Patients and methods}

$\nabla$

\section{Study design}

This study was conducted at the inpatient wards of National Cheng Kung University Hospital, a tertiary health care center in Tainan, Taiwan. The research and ethics committee of the hospital approved the study design (trial registration identifier: NCT02197039, ClincalTrials.gov), and all participants gave written informed consent before enrollment. A schematic flow chart of the study protocol is shown in $\bullet$ Fig. 1.

Eligible participants included patients aged $\geq 20$ years who had undergone gastroscopy for melena, hematochezia, or hematemesis due to bleeding peptic ulcers with major SRH. The major SRH were classified as Forrest Ia, Ib, Ila, and IIb types [16]. At the primary endoscopy, which was done within 24 hours of suspicious gastrointestinal bleeding on day 0 , the adherent clot was vigorously washed away, and all SRH patients were given one or a combination of endoscopic therapies including local injection of diluted epinephrine 1:10000, heater probe (HPU-20, Olympus, Tokyo, Japan) at 20J, bipolar electrocoagulation (ERBE ICC 200/ APC 300, ERBE Elektromedizin GmbH, Tübingen) at 30 watts, Forced Argon Plasma Coagulation (ERBE ICC 200/APC) at 60 watts per goal consecutively, band ligation, or hemoclip therapy until cessation of active bleeding or achievement of co-aptive coagulation $[3,4]$. Treatment procedures were performed by experienced endoscopists.

Patients were enrolled after successful endoscopic hemostasis. Each enrolled patient received an 80-mg loading dose of IV esomeprazole (Nexium ${ }^{\circledR}$, AstraZeneca AB, Södertälje, Sweden) immediately after hemostasis was achieved by gastroscopy. The patients then received 3 days of continuous high-dose $(8 \mathrm{mg} / \mathrm{h})$ IV esomeprazole as therapy [8]. Patients who took clopidogrel received the same doses and duration of IV pantoprazole (Pantoloc ${ }^{\circledR}$, Takeda, Singen, Germany) therapy. Patients taking warfarin or undergoing antiplatelet therapy discontinued such medications and therapies for 3 days after primary endoscopy.

The second-look endoscopy was scheduled on day 3, after postendoscopic hemostasis high-dose IV PPI therapy up to nearly 72 hours. If day 3 was Sunday or a holiday, the second-look endoscopy was conducted ahead of schedule on day 2 ( $\bullet$ Fig. 1). Otherwise, the second-look endoscopy was conducted immediately before the schedule if the patient had early clinically relevant rebleeding. Clinically relevant rebleeding was defined as: 1) continuous melena, hematochezia, or the presence of recurrent bloody aspirates through a nasogastric tube; and 2) relapse of hemodynamic instability, including systolic blood pressure $<90 \mathrm{mmHg}$, heart rate $>120$ beats/min, or a drop in hemoglobin concentration of $>2.0 \mathrm{~g} / \mathrm{dL}$. Patients were excluded if they had tumors, Dieulafoy, or mechanical factor-related bleeding (e.g., gastrostomy tube induction), PPI use for more than 1 day within a week before enrollment, hypersensitivity to esomeprazole or pantoprazole, had previously participated in the study, or had expired before the second-look endoscopy. 


\section{Predictive measures}

Patients were prospectively followed until the second-look endoscopy. The primary analytical goals were to characterize all patients and to identify predictors of early clinically relevant rebleeding or persistent major SRH at the second-look endoscopy through univariable and multivariable regression modeling. The patients' baseline clinical, laboratory, and endoscopic characteristics were obtained at the time of admission. The range of comorbidities was evaluated using the Rockall score [17]. Recent history of any major surgery within 14 days prior to bleeding, intensive care unit stay, mechanical ventilator support for $>24$ hours, exposure to nonsteroidal anti-inflammatory, sympathomimetic pressors, or inotropic drugs during the first 3 days after primary endoscopy was also evaluated. Nosocomial bleeding was defined as peptic ulcer bleeding that developed more than 24 hours after admission.

\section{Independent review of endoscopic pictures}

The endoscope employed was either an Olympus GIF-XQ230 or a 240 fibrescope. Ulcer size was estimated with biopsy forceps, with fully opened cups being $6 \mathrm{~mm}$ in diameter (FB-25K-1, Olympus). The endoscopists and staff who checked the gastroscopy were all blinded to the study. The investigator who enrolled the participants was not the same investigator who evaluated the Forrest type ulcers. A three-member steering committee provided quality assurance. All ulcer lesions and stigmata were photographed and then assessed by the committee. Independent review verified the endoscopic pictures to identify potential stigmata meeting the Forrest classification criteria [16]. Any stigmata considered equivocal by one of the reviewers was reviewed in full. An external observer audited whether the results were inconsistent between the investigators. Any disagreements were resolved by discussion and consensus. If the grading was still discrepant, patients were excluded.

\section{Statistical analysis}

We estimated the rate of persistent major SRH at second-look endoscopy to be $18 \%$ according to the average rebleeding rate (7.5\%) after the fourth day with current treatment protocols based on our previous trial [18], and the average rebleeding risk was estimated to be $40 \%$ with all major SRH cases [2]. In a prospective cohort study, assuming the proposed proportion exposed in the control group was 0.1 and that the proposed control-to-case ratio was $4.5(0.82 / 0.18)$, the statistical power for detecting an odds ratio (OR) of three would be $80 \%$ on the basis of 299 patients using a two-sided test at the $\alpha$ value of 0.05 . The estimated incidence of rebleeding during the first 72 hours before the schedule was proposed to be $5 \%[8,18]$, so at least 315 patients had to be included.

The patient characteristics were compared and tested using either the Pearson's $X^{2}$ test, Fisher's exact test, or the Student's $t$ test. Continuous variables were categorized to avoid multiplicative errors. Receiver operating characteristic (ROC) curves for determining cut-off values that best discriminated between groups were derived for each parameter, e.g. serum albumin levels. A multiple logistic regression analysis using selection of variables significant at the 0.20 level was applied to assess independent risk factors related to outcomes. The odds ratio obtained by the multiple logistic regression was transformed into the relative risk (RR) and its confidence interval ( $\mathrm{CI}$ ) was estimated directly with a statistical model to assess the predicted individual probabilities. We converted the RR transformed from the multiple lo- gistic regressions to indicate the weight for each significant prediction variable and produce a scoring system that required the addition of integer values. The scoring systems were trained and validated in a 10 -fold cross-validation strategy with 10 rounds of 10 repetitions [19]. All tests were two-tailed, and $P$ values less than 0.05 indicated significant differences.

\section{Results \\ $\nabla$}

\section{Demographic features and patient follow-up}

From August 2011 to July 2014, 474 patients with peptic ulcer bleeding were consecutively assessed for eligibility for this study $(\checkmark$ Fig. 1). One hundred and fifty-eight patients were excluded: 29 did not meet the inclusion criteria; 96 declined to participate; 12 had bleeding from gastric cancer, metastatic or other cancers; two died within 3 days; 18 had critical conditions; and one had discrepant SRH grading between reviewers.

Among the 316 patients that were included (96 females, 220 males), the mean age was 67.1 years, and 167 (52.8\%) had bleeding from gastric ulcers, 143 (45.3\%) from duodenal ulcers, and 6 (1.9\%) from anastomotic ulcers. There were 9 (2.8\%) Forrest type Ia, 97 (30.7\%) type Ib, 169 (53.5\%) type Ila, and 41 (13.0\%) type IIb ulcers. Forty-three patients (13.6\%) received endoscopic epinephrine-injection monotherapy with an average dose of 10 $\mathrm{mL}$ (range 8 to $15 \mathrm{~mL}$ ) of diluted epinephrine $1: 10,000,22(7.0 \%)$ received other endoscopic monotherapy, and 251 (79.4\%) received endoscopic combination therapies. Three hundred and five patients received esomeprazole, and 11 received pantoprazole.

Ten patients had early clinically relevant rebleeding and were designated as the "emergent group" for the second-look endoscopy. At the emergent second-look endoscopy, hemostatis was achieved in seven patients but two of them had rebleeding within 1 week. The remaining three patients received either emergent transarterial embolization or surgery.

Excluding 10 patients with early rebleeding, 306 patients were designated as the "scheduled group" and were further divided into either the Day-2 subgroup $(n=78)$ or the Day-3 subgroup $(n=228)$. Of all of the patients, one died suddenly during at the second-look endoscopy, and two patients had morbidity but did not die within 3 days of the second-look endoscopy, including one with sudden cardiac collapse and the other with duodenal perforation.

\section{Predictors of early clinical relevant rebleeding before second-look endoscopy}

- Table 1 demonstrates that early clinical relevant rebleeding was more common in patients with than without end-stage renal disease with maintenance dialysis, endoscopic epinephrine-injection monotherapy, or serum albumin levels $<3.0 \mathrm{~g} / \mathrm{dL}(P \leq$ $0.05)$. Multiple logistic regression confirmed that endoscopic epinephrine-injection monotherapy and serum albumin levels < $3.0 \mathrm{~g} / \mathrm{dL}$ were two independent risk factors $(P=0.002$ and 0.05 , respectively, $\bullet$ Table 1 ).

Based on these two independent risk factors for early peptic ulcer rebleeding, in this study, the E2 ${ }^{\text {nd }}$ (early second-look) score was created, which is the sum of the score from the initial endosopic therapies (score 2: epinephrine-injection monotherapy; score 0: others) plus the score of patient's serum albumin levels (score 1: $<3.0 \mathrm{~g} / \mathrm{dL}$; score 0 : $\geq 3.0 \mathrm{~g} / \mathrm{dL}$ ). The prediction rates from the E2 ${ }^{\text {nd }}$ score were increased in stepwise fashion in a trend from a score of 0 to $3(0.5 \%$ [1/201], $2.8 \%$ [2/72], 9.7\% [3/31], and 33.3\% [4/12], 
Table 1 Univariable analysis and multivariable logistic regression to determine factors associated with early clinical relevant rebleeding before the schedule

\begin{tabular}{|c|c|c|c|c|c|c|}
\hline \multirow[t]{2}{*}{ Variables, n (\%) } & \multicolumn{2}{|c|}{$\begin{array}{l}\text { Risks of early clinical relevant } \\
\text { rebleeding before the schedule }\end{array}$} & \multicolumn{2}{|l|}{ Univariable analysis } & \multicolumn{2}{|l|}{ Multivariable analysis } \\
\hline & With the variable & $\begin{array}{l}\text { Without the } \\
\text { variable }\end{array}$ & $\begin{array}{l}\text { Relative risk } \\
(95 \% \mathrm{Cl})\end{array}$ & $P$ value $^{1}$ & $\begin{array}{l}\text { Relative risk }{ }^{2} \\
(95 \% \mathrm{CI})\end{array}$ & $P$ value \\
\hline Female & $2 / 96(2.1)$ & $8 / 220(3.6)$ & $0.57(0.12-2.65)$ & 0.73 & - & - \\
\hline Age $\geq 70 \mathrm{y} / \mathrm{o}$ & $5 / 150(3.3)$ & $5 / 166(3.0)$ & $1.11(0.33-3.75)$ & 1.0 & - & - \\
\hline Hemodynamic instability ${ }^{3}$ & $2 / 60(3.3)$ & $8 / 256(3.1)$ & $1.07(0.23-4.90)$ & 1.0 & - & - \\
\hline Cirrhosis & $0 / 30(0)$ & $10 / 286(3.5)$ & 0 (NA) & 0.61 & - & - \\
\hline $\begin{array}{l}\text { End-stage renal disease with } \\
\text { maintenance dialysis }\end{array}$ & $3 / 28(10.7)$ & $7 / 288(2.4)$ & $4.41(1.21-16.11)$ & 0.05 & $1.69(0.46-6.19)$ & 0.63 \\
\hline Malignant diseases & $1 / 43(2.3)$ & $9 / 273(3.3)$ & $0.71(0.09-5.43)$ & 1.0 & - & - \\
\hline Lung diseases & $2 / 42(4.8)$ & $8 / 274(2.9)$ & $1.63(0.36-7.42)$ & 0.63 & - & - \\
\hline Nosocomial bleeding & $4 / 54(7.4)$ & $6 / 262(2.3)$ & $3.23(0.94-11.08)$ & 0.07 & $0.38(0.11-1.31)$ & 0.42 \\
\hline Rockall scores $\geq 6$ & $9 / 228(3.9)$ & $1 / 88(1.1)$ & $3.47(0.45-27.02)$ & 0.29 & - & - \\
\hline H. pylori infection ${ }^{4}$ & $1 / 133(0.8)$ & $6 / 158(3.8)$ & $0.20(0.02-1.62)$ & 0.13 & $0.14(0.02-1.13)$ & 0.14 \\
\hline NSAID use & $4 / 134(3.0)$ & $6 / 182(3.3)$ & $0.91(0.26-3.15)$ & 1.0 & - & - \\
\hline Aspirin use & $0 / 78(0)$ & $10 / 238(4.2)$ & $0(N A)$ & 0.13 & $0(\mathrm{NA})$ & 1.0 \\
\hline Ulcer $\geq 2 \mathrm{~cm}$ & $4 / 61(6.6)$ & $6 / 255(2.4)$ & $2.79(0.81-9.57)$ & 0.11 & $1.63(0.48-5.60)$ & 0.61 \\
\hline Forrest la or lb type & $4 / 106(3.8)$ & $6 / 210(2.9)$ & $1.32(0.38-4.58)$ & 0.74 & - & - \\
\hline Gastric high lesser curve ulcers & $1 / 9(11.1)$ & $9 / 307(2.9)$ & $3.79(0.54-26.82)$ & 0.25 & - & - \\
\hline Posterior duodenal ulcers & $1 / 22(4.5)$ & $9 / 294(3.1)$ & $1.49(0.20-11.19)$ & 0.52 & - & - \\
\hline $\begin{array}{l}\text { Endoscopic epinephrine-injection } \\
\text { monotherapy }\end{array}$ & $7 / 43(16.3)$ & $3 / 273(1.1)$ & $14.81(3.98-55.11)$ & $<0.001$ & $18.33(4.93-68.19)$ & 0.002 \\
\hline Hb levels $<10.0 \mathrm{~g} / \mathrm{dL}$ & $9 / 190(4.7)$ & $1 / 126(0.8)$ & $5.97(0.77-46.53)$ & 0.06 & $1.64(0.21-12.78)$ & 0.72 \\
\hline Platelet count $<80 \times 10^{9} / \mathrm{L}$ & $1 / 17(5.9)$ & $9 / 299(3.0)$ & $1.95(0.26-14.55)$ & 0.43 & - & - \\
\hline PT prolong $\geq 4$ seconds & $3 / 34(8.8)$ & $7 / 282(2.5)$ & $3.55(0.96-13.11)$ & 0.08 & $0.98(0.27-3.62)$ & 0.97 \\
\hline aPTT prolong $\geq 1.5$-fold & $1 / 4(25.0)$ & $9 / 312(2.9)$ & $8.67(1.41-53.24)$ & 0.12 & $0.47(0.08-2.90)$ & 1.0 \\
\hline Serum albumin levels $<3.0 \mathrm{~g} / \mathrm{dL}$ & $6 / 84(7.1)$ & $4 / 232(1.7)$ & $4.14(1.20-14.32)$ & 0.03 & $10.39(3.01-35.91)$ & 0.05 \\
\hline
\end{tabular}

aPTT, activated partial thromboplastin time; Cl, confidence interval; Hb, hemoglobin; H. pylori, Helicobacter pylori; NA, not available; NSAID, nonsteroidal anti-inflammatory drugs; PT, prothrombin time.

1 The Pearson's chi-square test and the Fisher's exact test with 2-tailed analysis were used as appropriate.

${ }^{2}$ The odds ratio obtained by multiple logistic regression was transformed into the relative risk and its confidence interval was estimated directly by a statistical model.

3 Systolic blood pressure $<100 \mathrm{mmHg}$ on arrival.

${ }^{4}$ The number of patients who received $H$. pylori infection survey was 291 . Activated partial thromboplastin time: normal range $26.0-38.0$ seconds. Hemoglobin: normal range $11.6-14.8 \mathrm{~g} / \mathrm{dL}$. Platelet: normal range $151-366 \times 10^{9} / \mathrm{L}$. Prothrombin time: normal range $9.40-12.5$ seconds. Serum albumin: normal range $3.5-5.0 \mathrm{~g} / \mathrm{dL}$.

$P<0.001)$, respectively. The area under the receiver operating characteristic curve (AUROC) of the E2 ${ }^{\text {nd }}$ score was 0.86 (95\% CI, $0.73-0.99$ ) ( Fig. 2). The ROC curve of the E2 ${ }^{\text {nd }}$ score showed the optimal value to be 2 . E2 ${ }^{\text {nd }}$ scores $\geq 2$ have a $70.0 \%$ sensitivity and $88.2 \%$ specificity for prediction of early rebleeding. The likelihood ratios for a positive test and negative test were found to be 5.95 and 0.34 , respectively.

Predictors of persistent major stigmata of recent hemorrhage at the second-look endoscopy

For patients in the scheduled group, there were no significant differences in clinical, endoscopic, and laboratory characteristics between the Day-2 subgroup and the Day-3 subgroup ( $\bullet$ Table 2 ), except for a higher rate of comorbid malignancy (16.7\% vs. $5.1 \%$, $P=0.01)$ and a lower rate of persistent major SRH (4.8\% vs. $15.4 \%$, $P=0.002)$ in the Day-3 subgroup as compared to the Day-2 subgroup.

Because the 24-hour shorter PPI infusion in the Day-2 subgroup with earlier second-look endoscopy may have served as a confounder limiting major SRH resolution, we simply enrolled the Day-3 subgroup with a nearly 72-hour standard duration of PPI infusion for the risk factor analysis related to persistent major SRH. As shown in Table 3, patients with Forrest Ia-Ib type ulcers or serum albumin levels $<3.5 \mathrm{~g} / \mathrm{dL}$ appeared to have evidence of more persistent major SRH than those who did not $(P<0.05)$. Multiple logistic regression confirmed that Forrest la-Ib type $(P$ $=0.001)$ and serum albumin levels $<3.5 \mathrm{~g} / \mathrm{dL}(P=0.047)$ were two independent risk factors for persistent major SRH ( $\bullet$ Table 3$)$. We thus derived a predictive model, the $\mathrm{R} 2^{\text {nd }}$ (routine second-look) score to predict persistent major SRH after a 72-hour PPI infusion. The R2 ${ }^{\text {nd }}$ score was created as follows: the $\mathrm{R} 2^{\text {nd }}$ score $=$ Forrest types (score 1: Ia-Ib; score 0: IIa-IIb)+serum albumin levels (score $1:<3.5 \mathrm{~g} / \mathrm{dL} ;$ score $0: \geq 3.5 \mathrm{~g} / \mathrm{dL}$ ). The prediction rates of the $\mathrm{R} 2^{\text {nd }}$ score in a range from 0 to 2 were increased stepwise $(1.4 \%$ [1/71], $0.8 \%$ [1/123], and 26.5\% [9/34], $P<0.001)$. The AUROC of the R2 ${ }^{\text {nd }}$ score was $0.84(95 \% \mathrm{CI}, 0.69-0.99)(\bullet$ Fig. 3). The ROC curve showed that an optimal $\mathrm{R} 2{ }^{\text {nd }}$ score of 2 had a sensitivity of $81.8 \%$ and a specificity of $88.5 \%$ for prediction of persistent major SRH after a 72-hour PPI infusion. The likelihood ratios for a positive test and negative test were 7.10 and 0.21 , respectively.

Number needing endoscopy based on E2 ${ }^{\text {nd }}$ and R2 ${ }^{\text {nd }}$ scores used to identify high-risk patients

The accuracy, sensitivity, specificity, and AUROC based on 10-fold cross-validation procedures were $87.7 \%, 70.0 \%, 88.2 \%$, and 0.852 for the E2 ${ }^{\text {nd }}$ score and $88.2 \%, 81.8 \%, 88.5 \%$, and 0.829 for the R2 ${ }^{\text {nd }}$ score, respectively. The Nagelkerke R-square scores were 0.285 and 0.294 , respectively. 


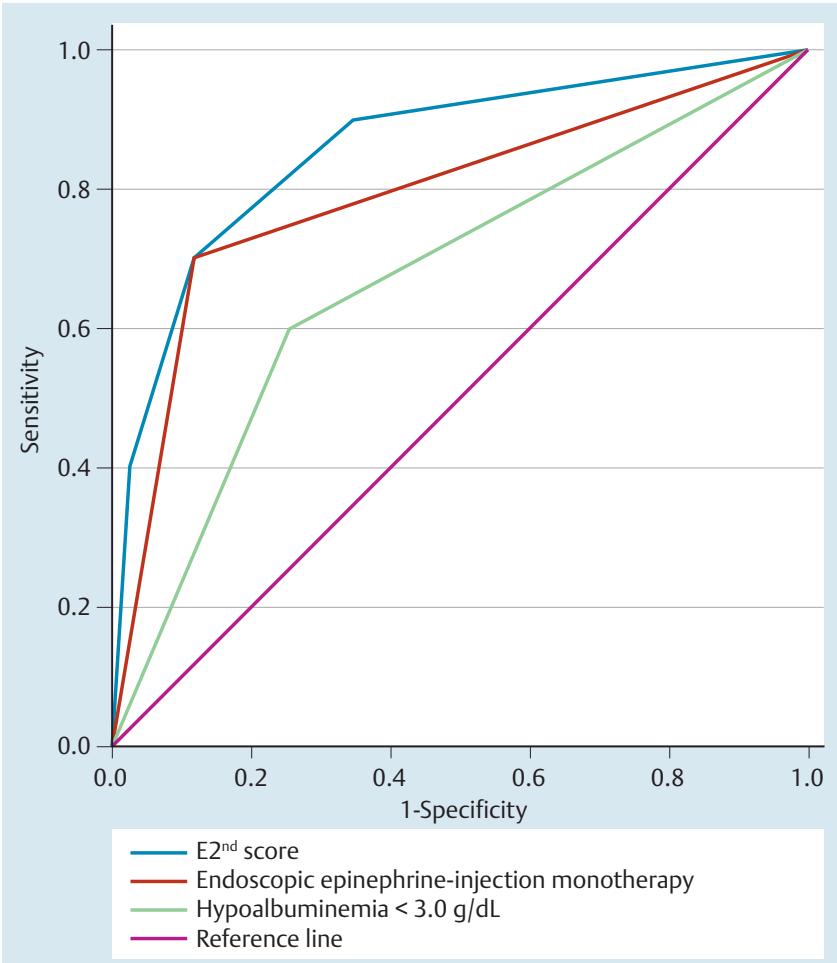

Fig. 2 Receiver operator characteristic curves for $\mathrm{E}{ }^{\text {nd }}$ score, endoscopic epinephrine-injection monotherapy, and hypoalbuminemia $<3.0 \mathrm{~g} / \mathrm{dL}$ to predict early clinically relevant recurrent bleeding. The data point was the measured index value.

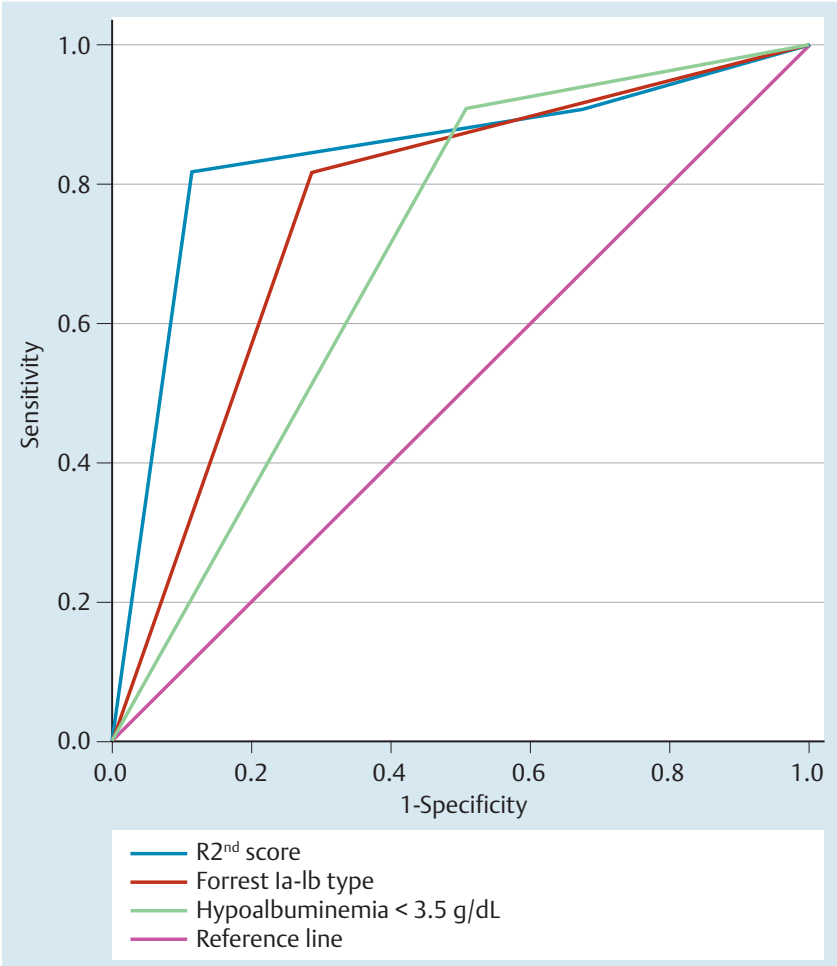

Fig. 3 Receiver operator characteristic curve for R2 ${ }^{\text {nd }}$ score, Forrest la-lb type and hypoalbuminemia $<3.5 \mathrm{~g} / \mathrm{dL}$ to predict persistent major SRH at the second-look endoscopy. The data point was the measured index value.
Table 2 Comparison of baseline characteristics of the Day-2 and Day-3 subgroups

\begin{tabular}{|c|c|c|c|}
\hline \multirow[t]{2}{*}{ Variables, N (\%), mean (SD) } & \multicolumn{3}{|c|}{ The scheduled group } \\
\hline & $\begin{array}{l}\text { The Day-2 } \\
\text { subgroup } \\
(\mathbf{n}=78)\end{array}$ & $\begin{array}{l}\text { The Day-3 } \\
\text { subgroup } \\
(\mathbf{n = 2 2 8 )}\end{array}$ & $P$ value $^{1}$ \\
\hline Female & $20(25.6)$ & $74(32.5)$ & 0.26 \\
\hline Age (years) & $66.7(15.4)$ & $67.3(13.6)$ & 0.72 \\
\hline Hemodynamic instability ${ }^{2}$ & $12(15.4)$ & $46(20.2)$ & 0.35 \\
\hline Cirrhosis & $4(5.1)$ & $26(11.4)$ & 0.11 \\
\hline $\begin{array}{l}\text { End-stage renal disease with } \\
\text { maintenance dialysis }\end{array}$ & $8(10.3)$ & $17(7.5)$ & 0.44 \\
\hline Malignant diseases & $4(5.1)$ & $38(16.7)$ & 0.01 \\
\hline Lung diseases & $7(9.0)$ & $33(14.5)$ & 0.21 \\
\hline Heart diseases & $16(20.5)$ & $49(21.5)$ & 0.86 \\
\hline Nosocomial bleeding & $9(11.5)$ & $41(18.0)$ & 0.18 \\
\hline ASA physical status class $\geq$ III & $37(47.4)$ & $117(51.3)$ & 0.55 \\
\hline Rockall scores $\geq 6$ & $52(66.7)$ & $166(72.8)$ & 0.30 \\
\hline H. pylori infection ${ }^{3}$ & $38(52.1)$ & $94(44.5)$ & 0.27 \\
\hline NSAID use & $30(38.5)$ & $100(43.9)$ & 0.41 \\
\hline Aspirin use & $18(23.1)$ & $60(26.3)$ & 0.57 \\
\hline $\begin{array}{l}\text { Any antiplatelet agent or } \\
\text { warfarin use }\end{array}$ & $28(35.9)$ & $83(36.4)$ & 0.94 \\
\hline Ulcer $\geq 2 \mathrm{~cm}$ & $16(20.5)$ & $41(18.0)$ & 0.62 \\
\hline Forrest la or lb type & $31(39.7)$ & $71(31.1)$ & 0.16 \\
\hline Gastric high lesser curve ulcers & $4(5.1)$ & $4(1.8)$ & 0.12 \\
\hline Posterior duodenal ulcers & $7(9.0)$ & $14(6.1)$ & 0.39 \\
\hline $\begin{array}{l}\text { Endoscopic epinephrine- } \\
\text { injection monotherapy }\end{array}$ & $12(15.4)$ & $24(10.5)$ & 0.25 \\
\hline Hb levels $<10.0 \mathrm{~g} / \mathrm{dL}$ & $43(55.1)$ & $138(60.5)$ & 0.40 \\
\hline Platelet count $<80 \times 10^{9} / \mathrm{L}$ & $5(6.4)$ & $11(4.8)$ & 0.56 \\
\hline PT prolong $\geq 4$ seconds & $5(6.4)$ & $26(11.4)$ & 0.21 \\
\hline aPTT prolong $\geq 1.5$-fold & $1(1.3)$ & $2(0.9)$ & 1.0 \\
\hline Serum albumin levels $<3.5 \mathrm{~g} / \mathrm{dL}$ & $36(46.2)$ & $120(52.6)$ & 0.32 \\
\hline
\end{tabular}

aPTT, activated partial thromboplastin time; ASA, American Society of Anesthesiology; $\mathrm{Cl}$, confidence interval; $\mathrm{Hb}$, hemoglobin; $H$. pylori, Helicobacter pylori; NSAID, nonsteroidal anti-inflammatory drugs; PT, prothrombin time; SD, standard deviation. ${ }^{1}$ The Pearson's chi-square test and the Fisher's exact test or the Student's $t$ test with 2-tailed analysis was used as appropriate.

2 Systolic blood pressure $<100 \mathrm{mmHg}$ on arrival.

${ }^{3}$ The number of patients who received $H$. pylori infection survey was 73 in the D2 subgroup and 211 in the D3 subgroup, respectively. Activated partial thromboplastin time: normal range 26.0-38.0 seconds. Hemoglobin: normal range 11.6$14.8 \mathrm{~g} / \mathrm{dL}$. Platelet: normal range $151-366 \times 10^{9} / \mathrm{L}$. Prothrombin time: normal range $9.40-12.5$ seconds. Serum albumin: normal range $3.5-5.0 \mathrm{~g} / \mathrm{dL}$.

We proposed a scenario to calculate the effectiveness of the $E 2^{\text {nd }}$ and $\mathrm{R} 2^{\text {nd }}$ scores. First, according to the $\mathrm{E} 2^{\text {nd }}$ scores that were $\geq 2$, $13.6 \%$ of the sample was selected to conduct early second-look endoscopy within 24 hours and might prevent $2.2 \%$ of patients from experiencing early rebleeding. Among patients with $E 2^{\text {nd }}$ scores $<2,1.0 \%$ had early rebleeding. Second, in the remaining $85.4 \%$, given $\mathrm{R} 2^{\text {nd }}$ scores of $2,12.7 \%$ of the sample was selected to conduct the second-look endoscopy, and $3.4 \%$ were identified with persistent major SRH. Of the patients with $\mathrm{R} 2{ }^{\text {nd }}$ scores $<2$, $0.7 \%$ had persistent major SRH. Finally, $26.3 \%$ of patients received second-look endoscopy, $5.6 \%$ of whom were found to have highrisk lesions. Thus, the positive rate for second-look endoscope would have been $21.3 \%$, which is higher than the $7.3 \%$ positive rate that would have been seen, had routine second-look endoscopy been conducted on all the patients. The absolute risk reduction for negative second-look endoscopy was $14.0 \%$, and the number needing endoscopy was 7.1. 
Table 3 Univariable analysis and multivariable logistic regression to determine factors associated with persistent major stigmata of recent hemorrhage at second-look endoscopy on day 3

\begin{tabular}{|c|c|c|c|c|c|c|}
\hline \multirow[t]{2}{*}{ Variables, N (\%) } & \multicolumn{2}{|c|}{$\begin{array}{l}\text { Risks of persistent major SRH at the } \\
\text { second-look endoscopy on day } 3\end{array}$} & \multicolumn{2}{|l|}{ Univariable analysis } & \multicolumn{2}{|l|}{ Multivariable analysis } \\
\hline & $\begin{array}{l}\text { With the } \\
\text { variable }\end{array}$ & $\begin{array}{l}\text { Without the } \\
\text { variable }\end{array}$ & $\begin{array}{l}\text { Relative risk } \\
(95 \% \mathrm{Cl})\end{array}$ & $P$ value $^{1}$ & $\begin{array}{l}\text { Relative risk }^{2} \\
(95 \% \mathrm{Cl})\end{array}$ & $P$ value \\
\hline Female & $5 / 74(6.8)$ & $6 / 154(3.9)$ & $1.73(0.55-5.50)$ & 0.34 & - & - \\
\hline Age $\geq 70 \mathrm{y} / 0$ & $5 / 105(4.8)$ & $6 / 123(4.9)$ & $0.98(0.31-3.11)$ & 0.97 & - & - \\
\hline Hemodynamic instability ${ }^{3}$ & $4 / 46(8.7)$ & $7 / 182(3.8)$ & $2.26(0.69-7.40)$ & 0.24 & - & - \\
\hline Cirrhosis & $2 / 26(7.7)$ & 9/202 (4.5) & $1.73(0.39-7.56)$ & 0.36 & - & - \\
\hline $\begin{array}{l}\text { End-stage renal disease with } \\
\text { maintenance dialysis }\end{array}$ & $1 / 17(5.9)$ & $10 / 211(4.7)$ & $1.24(0.17-9.13)$ & 0.58 & - & - \\
\hline Malignant diseases & $1 / 38(2.6)$ & $10 / 190(5.3)$ & $0.5(0.07-3.79)$ & 0.70 & - & - \\
\hline Lung diseases & $2 / 33(6.1)$ & 9/195 (4.6) & $1.31(0.30-5.81)$ & 0.66 & - & - \\
\hline Nosocomial bleeding & $3 / 41(7.3)$ & $8 / 187(4.3)$ & $1.71(0.47-6.17)$ & 0.42 & - & - \\
\hline Rockall scores $\geq 6$ & $8 / 166(4.8)$ & $3 / 62(4.8)$ & $1.0(0.27-3.63)$ & 1.0 & - & - \\
\hline H. pylori infection ${ }^{4}$ & $5 / 94(5.3)$ & $4 / 117(3.4)$ & $1.56(0.43-5.63)$ & 0.52 & - & - \\
\hline NSAID use & $5 / 100(5.0)$ & $6 / 128(4.7)$ & $1.07(0.34-3.40)$ & 1.0 & - & - \\
\hline Aspirin use & $5 / 60(8.3)$ & $6 / 168(3.6)$ & $2.33(0.74-7.37)$ & 0.16 & $2.39(0.76-7.56)$ & 0.20 \\
\hline Ulcer $\geq 2 \mathrm{~cm}$ & $4 / 41(9.8)$ & $7 / 187(3.7)$ & $2.61(0.80-8.49)$ & 0.11 & $2.56(0.79-8.33)$ & 0.19 \\
\hline Forrest la or lb type & $9 / 71(12.7)$ & $2 / 157(1.3)$ & $9.95(2.21-44.88)$ & 0.001 & $13.10(2.91-59.10)$ & 0.001 \\
\hline Gastric high lesser curve ulcers & $1 / 4(25.0)$ & $10 / 224(4.5)$ & $5.6(0.92-33.96)$ & 0.18 & $10.37(1.71-62.90)$ & 0.09 \\
\hline Posterior duodenal ulcers & $1 / 14(7.1)$ & $10 / 214(4.7)$ & $1.53(0.21-11.11)$ & 0.51 & - & - \\
\hline $\begin{array}{l}\text { Endoscopic epinephrine-injection } \\
\text { monotherapy }\end{array}$ & $0 / 24(0)$ & $11 / 204(5.4)$ & $0(\mathrm{NA})$ & 0.61 & - & - \\
\hline Hb levels $<10.0 \mathrm{~g} / \mathrm{dL}$ & $8 / 138(5.8)$ & $3 / 90(3.3)$ & $1.74(0.47-6.38)$ & 0.53 & - & - \\
\hline Platelet count $<80 \times 10^{9} / \mathrm{L}$ & $1 / 11(9.1)$ & $10 / 217(4.6)$ & $1.97(0.28-14.07)$ & 0.43 & - & - \\
\hline PT prolong $\geq 4$ seconds & $1 / 26(3.8)$ & $10 / 202(5.0)$ & $0.78(0.10-5.83)$ & 1.0 & - & - \\
\hline aPTT prolong $\geq 1.5$-fold & $0 / 2(0)$ & $11 / 226(4.9)$ & $0(\mathrm{NA})$ & 1.0 & - & - \\
\hline Serum albumin levels $<3.5 \mathrm{~g} / \mathrm{dL}$ & $10 / 120(8.3)$ & $1 / 108(0.9)$ & $9.0(1.17-69.16)$ & 0.01 & $7.99(1.04-61.41)$ & 0.049 \\
\hline
\end{tabular}

\section{Discussion}

This prospective study demonstrated that the $\mathrm{E} 2^{\text {nd }}$ score can predict early clinically relevant rebleeding. Patients who received IV PPI infusion for a longer duration achieved more major SRH resolution. The $\mathrm{R} 2^{\text {nd }}$ score had good negative predictive value for persistent major SRH after adequate PPI infusion.

Endoscopic epinephrine-injection monotherapy has been reported to be strongly predictive of endoscopic treatment failure $[3,4,12,20]$. Our findings not only strengthen this supposition, but also illustrate that hypoalbuminemia $<3.0 \mathrm{~g} / \mathrm{dL}$ is another significant independent risk factor for early peptic ulcer rebleeding ( $\odot$ Table 1). Based on the combination of these two risk factors, our E2 ${ }^{\text {nd }}$ score can accurately predict early peptic ulcer rebleeding ( 0 Fig. 2). Because most rebleeding develops within 24 hours [21], adding an early second endoscopic treatment within 24 hours should be considered to reduce rebleeding risk $[3,22]$. It would be highly original to offer a simple score to indicate the need for an early second-look endoscopy.

Most trials conducted to evaluate the impact of second-look endoscopy for peptic ulcer bleeding were based on non-PPI or non-high-dose PPI therapy [5-7]. Because preemptive highdose IV PPI therapy accelerates SRH resolution $[23,24]$, it is necessary to validate whether additional high-dose IV PPI therapy after endoscopic hemostasis could improve the fading of SRH and thus decrease the need for second-look endoscopy. Our study design was highly original in that it offered a time-course comparison of SRH fading according to the high-dose PPI infusion typically used in peptic ulcer bleeding. Our data showed that there were higher rates of persistent major SRH in the Day-2 subgroup than in the Day-3 subgroup ( $15.4 \%$ vs. $4.8 \%, P=0.002$ ). These data imply that once high-dose PPI infusion is initiated, it is rational to administer it for at least 3 days to achieve better SRH fading of peptic ulcer bleeding. Nevertheless, nearly $4.8 \%$ of patients under consideration still needed a second-look endoscopy to improve the control of rebleeding risk.

The particularly striking finding from this study was that our R2 ${ }^{\text {nd }}$ score combined with the Forrest la-Ib type and serum albumin levels $<3.5 \mathrm{~g} / \mathrm{dL}$ could predict persistent major SRH on day 3 $(\bullet$ Table 3). A recent Cochrane review showed that for Forrest IaIb type ulcers, endoscopic combined therapies reduce rebleeding risks [25]. Nevertheless, our study showed that 9 of 11 patients who still had persistent major SRH on day 3 had Forrest Ia-Ib type ulcers at primary endoscopy, all of whom received endoscopic combined therapies. Interestingly, the serum albumin levels in these patients all were $<3.5 \mathrm{~g} / \mathrm{dL}$. Therefore, this study not only reinforced the important role of endoscopic features [2], but also raised the potential role of hypoalbuminemia in outcomes related to peptic ulcer bleeding. 
The reasons why hypoalbuminemia was such a strong predictor are uncertain. The serum albumin level is disease-specific, and it indirectly reflects the nutritional status of both acute and chronically ill patients [26,27]. AIMS65 scores and other trials also have revealed that hypoalbuminemia is an outcome predictor in upper gastrointestinal bleeding [14,28-30]. Furthermore, our study showed that combined with serum albumin levels, $E 2^{\text {nd }}$ and $\mathrm{R} 2^{\text {nd }}$ scores were better able to predict outcomes than do endoscopic features alone ( $\bullet$ Fig. 2 and $\bullet$ Fig.3). Neither hypoalbuminemia nor albumin administration resulted in significant changes in the free plasma concentration or in the pharmacologic effect of omeprazole [31]. Therefore, we propose that hypoalbuminemia can serve as a simple biomarker of comorbidity.

Second-look endoscopy is a very high-cost and invasive intervention. Previous education practices have suggested that "where high-dose IV PPI therapy was commenced, routine second-look endoscopy was not necessary" [32]. In this study, we used contemporary strategies and found that most patients really did not need routine second-look endoscopy, but it was still indicated for a high-risk group, such as can be selected using $E 2^{\text {nd }}$ scores $\geq 2$ or $\mathrm{R} 2^{\text {nd }}$ scores $=2$ for which the estimated number suggesting the need to scope was 7.1. Because selective second-look endoscopy may be cost-effective if the number is $\leq 10$ [33], our data suggest that it could be generalizable to current clinical practice to help reduce the risk of rebleeding in high-risk patients.

Our study had some limitations. First, the primary outcomes were early rebleeding and persistent major SRH, rather than long-term rebleeding or mortality. However, the clinical benefit of therapeutic endoscopy for high-risk stigmata has been proven $[3,4,19,34]$. Second, the patients were divided into the Day-2 or Day-3 subgroups in a non-randomized manner. However, we enrolled almost all patients with peptic ulcer bleeding in our hospital consecutively to reduce potential enrollment bias. Moreover, there were no significant differences between the two subgroups in baseline characteristics. Third, we might have missed other risk factors that have been reported to correlate with endoscopic hemostasis failure [35], e.g., ulcer size $\geq 2 \mathrm{~cm}$ because of relative risks $<3$. Of note, these risk factors were not significant because the effects were accounted for by more significant factors.

In conclusion, $\mathrm{E} 2^{\text {nd }}$ and $\mathrm{R} 2^{\text {nd }}$ scores, including both endoscopic features and serum albumin levels, could predict the need for early and routine second-look endoscopy, respectively. Only two parameters are needed for each score, thus the calculation can be made easily and its use is intuitive. Even when high-dose PPI infusion is administered, routine second-look endoscopy should be considered based on $\mathrm{R} 2^{\text {nd }}$ score, as a cost-effective treatment of high-risk patients.

\section{Competing interests: None}

\section{Acknowledgements}

We are grateful to Professor Sheng-Hsiang Lin for providing statistical consulting services from the Biostatistics Consulting Center, National Cheng Kung University Hospital. This study was funded in part by research grants from the Ministry of Science and Technology (National Science Council) of Taiwan (NSC 1002314-B-006-026-MY3), the National Cheng Kung University Hospital in Tainan, Taiwan (NCKUH-10104002 and NCKUEDA10207), and the E-DA Hospital in Kaohsiung, Taiwan (NCKUEDA10207).

\section{References}

1 Marmo R, Koch M, Cipolletta L et al. Predicting mortality in non-variceal upper gastrointestinal bleeders: validation of the Italian PNED score and prospective comparison with the Rockall score. Am J Gastroenterol 2010; 105: 1284-1291

2 Laine L, Peterson WL. Bleeding peptic ulcer. N Engl J Med 1994; 331: 717-727

3 Laine L, McQuaid KR. Endoscopic therapy for bleeding ulcers: an evidence-based approach based on meta-analyses of randomized controlled trials. Clin Gastroenterol Hepatol 2009; 7: 33-47

4 Barkun AN, Martel M, Toubouti Y et al. Endoscopic hemostasis in peptic ulcer bleeding for patients with high-risk lesions: a series of meta-analyses. Gastrointest Endosc 2009; 69: 786 - 799

5 Villanueva C, Balanzó J, Torras X et al. Value of second-look endoscopy after injection therapy for bleeding peptic ulcer: a prospective and randomized trial. Gastrointest Endosc 1994; 40: 34- 39

6 Saeed ZA, Cole RA, Ramirez FC et al. Endoscopic retreatment after successful initial hemostasis prevents ulcer rebleeding: a prospective randomized trial. Endoscopy 1996; 28: 288-294

7 Chiu PW, Lam CY, Lee SW et al. Effect of scheduled second therapeutic endoscopy on peptic ulcer rebleeding: a prospective randomised trial. Gut 2003; 52: $1403-1407$

8 Sung JJ, Barkun A, Kulpers EJ et al. Intravenous esomeprazole for prevention of recurrent peptic ulcer bleeding. Ann Intern Med 2009; 150: $455-464$

9 Sung JJ, Chan FK, Chen M et al. Asia-Pacific working group consensus on non-variceal upper gastrointestinal bleeding. Gut 2011; 60: 11701177

10 Marmo R, Rotondano G, Bianco MA et al. Outcome of endoscopic treatment for peptic ulcer bleeding: Is a second look necessary? A meta-analysis Gastrointest Endosc 2003; 57: 62 -67

11 El Ouali S, Barkun AN, Wyse J et al. Is routine second-look endoscopy effective after endoscopic hemostasis in acute peptic ulcer bleeding? A meta-analysis Gastrointest Endosc 2012; 76: 283-292

12 Sheu $B S, W u C Y, W u$ MS et al. Consensus on control of risky nonvariceal upper gastrointestinal bleeding in taiwan with national health insurance. Biomed Res Int 2014; 2014: 563707

13 Cheng HC, Chuang SA, Kao YH et al. Increased risk of rebleeding of peptic ulcer bleeding in patients with comorbid illness receiving omeprazole infusion. Hepatogastroenterology 2003; 50: 2270-2273

14 Cheng $H C$, Kao AW, Chuang CH et al. The efficacy of high and low dose intravenous omeprazole in preventing rebleeding for patients with bleeding peptic ulcers and comorbid illnesses. Dig Dis Sci 2005; 50: $1194-1201$

15 Barkun AN, Bardou M, Kuipers EJ et al. Internal Consensus Upper Gastrointestinal Bleeding Conference Group. International consensus recommendations on the management of patients with nonvariceal upper gastrointestinal bleeding. Ann Intern Med 2010; 152: 101 - 113

16 Forrest JA, Finlayson ND, Sherman DJ. Endoscopy in gastrointestinal bleeding. Lancet 1974; 2: 394-397

17 Rockall TA, Logan RF, Devlin HB et al. Risk assessment after acute upper gastrointestinal haemorrhage. Gut 1996; 38: 316-321

18 Cheng HC, Wu CT, Chang WL et al. Double oral esomeprazole after three-day intravenous esomeprazole infusion reduces recurrent peptic ulcer bleeding in high-risk patients-a randomized controlled study. Gut 2014; 63: $1864-1872$

19 Kohavi R. A study of cross-validation and bootstrap for accuracy estimation and model selection. In: Proceedings of the 14th International Joint Conference on Artificial Intelligence. 2: Volume San Francisco: Morgan Kaufmann; IJCAI (US); 1995: 1137-1143

20 Calvet $X$, Vergara $M$, Brullet $E$ et al. Addition of a second endoscopic treatment following epinephrine injection improves outcome in highrisk bleeding ulcers. Gastroenterology 2004; 126: 441-450

21 Lin HJ, Perng CL, Lee FY et al. Clinical courses and predictors for rebleeding in patients with peptic ulcers and non-bleeding visible vessels: a prospective study. Gut 1994; 35: 1389-1393

22 Pescatore P, Jornod P, Borovicka J et al. Epinephrine versus epinephrine plus fibrin glue injection in peptic ulcer bleeding: a prospective randomized trial. Gastrointest Endosc 2002; 55: 348-353

23 Lau JY, Leung WK, Wu JC et al. Omeprazole before endoscopy in patients with gastrointestinal bleeding. N Eng J Med 2007; 356: 1631 1640

24 Sreedharan A, Martin J, Leontiadis GI et al. Proton pump inhibitor treatment initiated prior to endoscopic diagnosis in upper gastrointestinal 
bleeding (Review). Cochrane Database Syst Rev 2010; 7: CD005415. pub3. DOI 10.1002/14651858.CD005415.pub3

25 Vergara $M$, Bennett $C$, Calvet $X$ et al. Epinephrine injection versus epinephrine injection and a second endoscopic method in high-risk bleeding ulcers. Cochrane Database Syst Rev 2014; 10: CD005584 DOI 10.1002/14651858

26 Jellinge ME, Henriksen DP, Hallas $P$ et al. Hypoalbuminemia is a strong predictor of 30-day all-cause mortality in acutely admitted medical patients: a prospective, observational, cohort study. PloS One 2014; 9: e105983

27 Chojkier M. Inhibition of albumin synthesis in chronic diseases molecular mechanisms. J Clin Gastroenterol 2005; 39: 143-146

28 Cheng HC, Chang WL, Yeh YC et al. Seven-day intravenous low-dose omeprazole infusion reduces peptic ulcer rebleeding for patients with comorbidities. Gastrointest Endosc 2009; 70: 433-439

29 Hyett BH, Abougergi MS, Charpentier JP et al. The AIMS65 score compared with the Glasgow-Blatchford score in predicting outcomes in upper GI bleeding. Gastrointest Endosc 2013; 77: 551-557
30 Cheng $H C$, Chang WL, Chen WY et al. Intravenous albumin shortens the duration of hospitalization for patients with hypoalbuminemia and bleeding peptic ulcers: a pilot study. Dig Dis Sci 2013; 58: 3232 - 3241

31 Regardh CG, Gabrielsson M, Hoffman KJ et al. Pharmacokinetics and metabolism of omeprazole in animals and man-an overview. Scand J Gastroenterol 1985; 108: (Suppl) 79-94

32 Chiu PW, Sung JJ. High risk ulcer bleeding: when is second-look endoscopy recommended? Clin Gastroenterol Hepatol 2010; 8: 651-654

33 Spiegel BM, Ofman JJ, Woods $K$ et al. Minimizing recurrent peptic ulcer hemorrhage after endoscopic hemostasis: the cost-effectiveness of competing strategies. Am J Gastroenterol 2003; 98: 86-97

34 Marmo R, Rotondano G, Piscopo R et al. Dual therapy versus monotherapy in the endoscopic treatment of high-risk bleeding ulcers: a metaanalysis of controlled trials. Am J Gastroenterol 2007; 102: 279-289

35 Elmunzer BJ, Young SD, Inadomi JM et al. Systematic review of the predictors of recurrent hemorrhage after endoscopic hemostatic therapy for bleeding peptic ulcers. Am J Gastroenterol 2008; 103: 2625 - 2632 